\title{
Masters of the Universe. Hayek, Friedman, and the Birth of Neoliberal Politics
}

\author{
Título: Masters of the Universe. Hayek, Friedman, and the Birth of Neoliberal Politics \\ Autor: Daniel Stedman Jones \\ Edición: Princeton University Press, 2012, 418 pp. \\ Carlos RoDRÍGUEZ BRAUN \\ Universidad Complutense de Madrid
}

La cubierta de este libro muestra cuatro fotografías del mismo tamaño, las de Hayek y Friedman en la parte superior, y las de Thatcher y Reagan en la inferior. Todos sonríen. Y el título es: Masters of the Universe. El objetivo de Daniel Stedman Jones es triple: primero, explicar cómo se extendieron las ideas liberales sobre el control de la inflación, la reducción del intervencionismo y la extensión de las reformas liberalizadoras; segundo, explicar cómo esas ideas se impusieron en las políticas de los gobiernos del Reino Unido y Estados Unidos; y tercero, explicar cómo esas ideas triunfantes en el mundo dieron como resultado desastres sin paliativos. Logra el primer objetivo, y hace bastante el ridículo en los otros dos.

$\mathrm{Su}$ relato sobre la difusión del mensaje liberal, en efecto, merece la calificación de "equilibrado y matizado" con la que The Economist homenajeó exageradamente a todo el texto. Describe bien a los más destacados economistas liberales, que incluyen a los dos ya mencionados pero también a Mises, Buchanan, Stigler y otros, y es aceptablemente preciso en su historia de las instituciones que los liberales establecen, empezando por la Mont Pelerin Society (de la que soy miembro), fundada en 1947. Se apoya en fuentes conocidas, a veces deficientes, como Mirowski y a veces solventes, como la historia de la Mont Pelerin Society que escribió Max Hartwell, conocido historiador económico y antiguo presidente de la Sociedad, que actualmente tiene al primer presidente español de su historia: Pedro Schwartz.

El recorrido de las instituciones liberales también es un acierto del libro, que las analiza en las dos orillas del Atlántico, prestando atención a think tanks de la relevancia del Institute of Economic Affairs de Londres y el Cato Institute de Washington D.C.

Es asimismo fiel a los matices dentro de los liberales, que incluso en el seno de la Mont Pelerin Society han chocado a menudo, siendo destacados los enfrentamientos entre los partidarios de las escuelas austriaca y de Chicago en torno a problemas monetarios. Se podrían mencionar otros, no recogidos en el libro, como las críticas de Anthony de Jasay, quizá el más sólido y original pensador liberal vivo, a Popper y a Hayek -los tres, miembros de la Mont Pelerin Society.

Pero los matices conspiran contra los otros dos objetivos del autor, y de ahí que no pueda sacarles el jugo que merecen, singularmente en el caso de uno que con justicia señala: el llamado neoliberalismo, incorrectamente asociado a la derecha, es transversal, y al mismo tiempo que Reagan y Thatcher privatizaban empresas públicas o abrían mercados, hacían lo propio Felipe González, Carlos Andrés Pérez o Carlos Menem, entre otros gobernantes de ideología variopinta. Esto ilumina otra característica del neoliberalismo: su carácter confuso y contradictorio, y su habitual lejanía del liberalismo clásico, porque dichos mandatarios, y muchos otros también denostados por su neoliberalismo, tomaron algunas medidas liberalizadoras y privatizadoras, pero expandieron notablemente los impuestos, el gasto y la deuda públicos, justo al revés de lo que el liberalismo propugna.

De todas formas, esa confluencia de políticas económicas no es una excepción (a partir de 2007, por ejemplo, todos los gobiernos de todos los países subieron los impuestos) pero dar cuenta de ello requiere una teoría adecuada sobre el Estado: entre la ausencia de esa teoría y la presencia de prejuicios, los errores se acumulan.

Las distorsiones del liberalismo son patentes. Por ejemplo, es una "fe" (pp. 212, 270, 329, $341,344)$, como si el antiliberalismo fuera una ciencia, y los liberales son malvados dogmáticos vociferantes que atacan a los pobres y anhelan la desigualdad (pp. 9, 63, 76, 330, 333, 338). Si 
se les entiende, es sólo porque son "engañosamente sencillos" (pp. 201, 211). Y el mercado es salvaje y frío, como si su ausencia fuera civilizada y cálida (pp. 70, 86).

No faltan fábulas notorias, como que el New Deal de Franklin D. Roosevelt fue excelente para los trabajadores, algo que se puede sostener ignorando los datos, o que el liberalismo es una utopía igual que el socialismo, como si no contaran los cien millones de trabajadores víctimas del antiliberalismo real más desaforado. Keynes es el héroe porque rescató al capitalismo, reiterado dislate que pasa por encima del hecho de que el Estado jamás consulta a todos los capitalistas y trabajadores sobre si quieren perder su libertad: se la arrebata y siempre habrá portavoces vehementes o simplemente ignaros que desde púlpitos, cátedras y tribunas sin fin insistan en que la libertad es una estafa y que el pueblo necesita líderes que violen sus derechos por su bien.

Esto se asocia con la habitual ficción, ligada a la tesis de la doble utopía liberalismo/socialismo, de que el óptimo social es siempre un punto intermedio entre ambos, como si fueran extremos análogamente nocivos, tesis característica de los estatistas de todos los partidos: no por casualidad llamó Mussolini a Roosevelt un vero fascista. Esta pretendidamente virtuosa middle way, vastamente popular, se apoya en la fantasía que interpreta la libertad de los ciudadanos como algo peligroso cuyos excesos deben ser morigerados por la benéfica coacción política y legislativa.

Algunas equivocaciones teóricas de Stedman Jones son notables, como afirmar que los austriacos no tenían una teoría de las expectativas, que ya están en Menger, economista, por cierto, que no es aquí incluido en la Revolución Marginal. En el caso de Hayek, "la moral casi siempre estuvo ausente de sus escritos" (p. 112), algo insostenible. Sitúa a J.S. Mill en la línea liberal entre Smith y Hayek, aunque aclara que sólo en Sobre la libertad, idea también cuestionable (cf. On Liberty's Liberty). Repite consignas infundadas, como que el liberalismo se basa en la llamada teoría del derrame o trickle-down theory (pp. 265, 334), lo que no tiene fundamento, como han demostrado entre otros Sowell y Lal. Y otro viejo error es afirmar que los economistas clásicos creían que la economía estaba siempre en o siempre confluyendo hacia un equilibrio con pleno empleo (p. 186).

El error práctico más notable, y más grave para un libro que presume de denunciar el triunfo del liberalismo es precisamente que sólo lo denuncia, sin matiz alguno, y nunca lo prueba, porque es imposible de probar. Llega al desvarío de diagnosticar la "destrucción de la esfera pública" (p. 271); "el mercado libre fue casi universalmente aceptado" (p. 328) por unos gobernantes perversos que acometieron "recortes salvajes" para "mercantilizar totalmente" los servicios públicos (pp. 341-3): las cifras, como sabe cualquiera que se moleste en consultarlas, prueban lo contrario, incluso en los países a los que presta más atención, Estados Unidos y Gran Bretaña, bajo los odiosos gobiernos de Thatcher y Reagan.

La supuesta victoria arrasadora del liberalismo no se compadece con los hechos: los infortunios y contratiempos indudables que ha padecido la población no pueden haber sido causados por un estrechamiento del sector público, que no se produjo en ningún país del mundo. Dicha extendida fantasía resulta particularmente desatinada vista desde España, donde el peso del gasto público sobre el PIB no llegaba al $25 \%$ en las postrimerías de la dictadura franquista, y trepó hasta el $50 \%$ en la crisis de 1992-93; crisis, que, como todas, como siempre, fue atribuida a un exceso de libertad, incluso por muchos académicos que no se molestaron en mirar los datos, igual que tantos no miran ni los datos ni la teoría cuando nos aseguran que la libertad conduce al "colapso de la comunidad" (p. 344), o proclaman que el mundo de la economía académica era mayoritariamente liberal (o incluso, en el colmo de la inopia analítica, "ultraliberal"), y que ahora gracias a Dios ha visto la luz, subraya los fallos del mercado y recomienda soluciones intervencionistas, que es precisamente lo que la mayoría de la profesión viene haciendo desde Jevons y Walras hasta Stiglitz.

Este es un libro fundamentalmente anglosajón, y por eso es recomendable leerlo junto con Las tribus liberales, que María Blanco publicó recientemente en Ediciones Deusto. El contraste permite ratificar una diferencia entre el mundo anglosajón y el resto: entre los anglosajones hay un cierto número de empresarios que están dispuestos a apoyar las ideas liberales: en España no hay nada parecido en volumen e influencia a los think tanks liberales americanos y británicos. 
Basta con comparar cualquiera de los más destacados allí con el Instituto Juan de Mariana, la principal institución liberal española, donde el apoyo empresarial más bien brilla por su ausencia, y cuyo director, Juan Ramón Rallo, fue expulsado de la televisión pública española bajo el gobierno de derechas de Mariano Rajoy; el mismo que, a pesar de ser acusado de una cruel y excesiva "austeridad", y de haber perpetrado igualmente vesánicos "recortes", subió los impuestos y no redujo el gasto público, en diáfana refutación del supuesto predominio del liberalismo, un predominio que sólo ha existido en las mentes algodonosas convencionales, más acostumbradas al automatismo que al ejercicio.

Como suele ocurrir en las novelas, la cumbre de la ficción llega al final, cuando el autor no sólo nos asegura que la crisis fue culpa de la libertad, lo que no tiene ningún aval empírico, sino que proclama que con la crisis la libertad se ha consolidado, y los que redujeron el Estado antes han continuado con su siniestro empeño. Los impuestos, el gasto público y la deuda pública alcanzan niveles récord, pero Stedman Jones nos asegura que estamos en manos de los liberales, que siempre han recomendado lo contrario.

Termino con una reivindicación de nuestras universidades y de nuestros profesores, tantas veces señalados como paradigmas exclusivos de la mediocridad y la ignorancia. Este señor, que habla seriamente de la "apoteosis de la fe liberal en los mercados libres" (p. 338) cuando la realidad apunta en sentido contrario, no es español, es inglés, es licenciado por la Universidad de Oxford y doctor por la de Pennsylvania. Y sus equivocaciones en forma de libro las publica la Universidad de Princeton. 